\title{
EFEKTIFIVITAS REALISASI PROGRAM ALOKASI DANA DESA (ADD) DI DESA GELAMPANG WIH TENANG UKEN KECAMATAN PERMATA KABUPATEN BENER MERIAH
}

\author{
Effectiveness Of Realization Of The Village Fund Allocation Program (Add) In Genampang \\ Wih Muscle Village District General Regency Of Bener Regency
}

\author{
Irfan Hidayat, Zulkarnain ${ }^{1}$ Lukman Hakim $^{1^{*}}$, \\ ${ }^{1}$ Program Studi Agribisnis, Fakultas Pertanian, Universitas Syiah Kuala
}

\begin{abstract}
Abstrak. ADD di maksudkan untuk meningkatkan efektifitas dan efisiensi penyelesaian masalah yang berskala desa secara langsung maupun yang berskala daerah secara tidak langsung. Permasalahan desa bersama masyarakatnya, sangatlah spesifik dan tidak dapat di sama-ratakan untuk setiap desa. Desa Gelampang Wih Tenang Uken Adalah salah satu desa yang terletak di Kabupaten Bener Meriah yang mendapatkan anggaran dana desa. Sejak tahun 2015 dana desa yang sudah di terima yaitu Rp.222.699.900,00. Dan terus mengalami peningkatan pada tahun 2017 Desa Gelampang Wih Tenang Uken Sudah menerima anggaran dana desa sebesar Rp. 973.351.708,00. Hasil penelitian ini adalah realisasi kegiatan Program ADD yang dilakukan di Desa Gelampang Wih Tenang Uken yaitu pembangunan berbentuk fisik diantaranya pembangunan rabat beton, drainase, turap kantor desa dan pembanguanan jalan pemukiman/aspal lapen. Implementasi Program ADD di Desa Gelampang Wih Tenang Uken terkendala pada kurangnya transfaransi pemerintah desa sehingga informasi yang di berikan terbatas. Realisasi program Alokasi Dana Desa (ADD) di Desa Gelampang Wih Tenang Uken tergolong efektif, hal ini dapat dilihat dari laporan pertanggung jawaban desa di mulai dari tahun 2015 $(222.699 .900: 300.000 .000 \times 100 \%=74,23 \%), 2016(611.174 .000: 750.000 .000 \times 100 \%=81,49 \%)$ 2017, (973.351.708: 1.000.000.000 x 100\% = 97,33\%). Namun demikian, pengelolaan ADD di Desa Gelampang Wih Tenang Uken masih perlu perbaikan baik di segi pengelolaan maupun sumberdaya manusia.
\end{abstract}

Kata kunci: Efektivitas, Realisasi, Implementasi, ADD

Abstract. ADD is intended to improve the effectiveness and efficiency of village-scale problem solving directly or indirectly. The village issue with the community is very specific and can not be equally shared for each village. Desa Gelampang Wih Tenang Uken It is one of the villages located in Bener Meriah Regency that get the village budget. Since 2015 the village funds already received are Rp.222.699.900,00. And continue to increase in 2017 Desa Gelampang Wih Tenang Uken It has received budget of village fund equal to $\mathrm{Rp} .973 .351 .708,00$. The result of this research is the realization of ADD program activities conducted in Gelampang Wih Tenang Uken Village which is physical development such as construction of concrete rebound, drainage, plastering of village office and construction of residential / asphalt road. The implementation of ADD Program in Gelampang Wih Tenang Village is constrained on the lack of transparency of village government so that the information given is limited. The realization of the Village Fund Allocation (ADD) program in Gelampang Wih Tenang Village Uken is effective, this can be seen from the village accountability report starting from $2015(222.699 .900: 300.000 .000 \times 100 \%=74.23 \%), 2016(611,174,000: 750,000,000 \times 100 \%=$ $81.49 \%) 2017,(973,351,708: 1,000,000,000 \times 100 \%=97.33 \%)$. However, the management of ADD in Gelampang Wih Tenang village still needs improvement both in terms of management and human resources.

Keywords: Effectiveness, Realization, Implementation, ADD 


\section{PENDAHULUAN}

Dewasa ini pemerintah Indonesia terus mengupayakan peningkatan pelaksanaan pembangunan nasional agar laju pembangunan daerah serta laju pembangunan desa dan kota semakin seimbang dan serasi. Namun pembangunan nasional pada pelaksanaannya masih dihadapkan dengan masalah pokok pembangunan seperti ketimpangan pembangunan antara desa dan kota di Indonesia.

Menanggapi permasalahan tersebut, pemerintah memberi dukungan keuangan kepada desa salah satunya adalah berasal dari dana perimbangan keuangan antara Pemerintah Pusat dan Pemerintah Daerah minimal 10\% diperuntukkan bagi desa yang disebut ADD. Maksud pemberian ADD sebenarnya adalah sebagai bantuan stimulan atau dana perangsang untuk mendorong dalam membiayai program pemerintah desa yang ditunjang dengan partisipasi swadaya gotong royong masyarakat dalam melaksanakan kegiatan pemerintahan dan pemberdayaan masyarakat. (Rozaki,2005)

Besaran alokasi anggaran yang diperuntukan langsung ke desa ditentukan 10 persen dari dalam dan di luar dana transfer ke daerah secara bertahap. Merujuk pada ketentuan Pasal 72 UU Desa, pendapatan desa yang bersumber dari alokasi APBN, atau dana desa bersumber dari belanja pusat dengan mengefektifkan program yang berbasis desa secara merata dan berkeadilan.Pencairan dana bertahap juga didasarkan dengan mempertimbangkan kemampuan APBN dan fiskal nasional. Tidak hanya itu, pemerintah juga mempertimbangkan kesiapan kabupaten/kota dalam melakukan pembinaan, pengawasan, serta kesiapan desa dalam melaksanakan pembangunan desa.

Pemerintah Aceh tahun 2016 mendapatkan Alokasi Dana Desa (ADD) dari pemerintah pusat sebesar Rp 3,8 triliun. Jumlah itu meningkat 100 persen lebih dibandingkan jatah tahun 2015 sebesar Rp 1,7 triliun. dana dari APBN tersebut nantinya akan diperuntukkan bagi 6.474 gampong yang tersebar di 23 kabupaten/kota di Aceh. Sekitar 90 persen dari total dana itu akan dibagi rata sebagai alokasi dasar untuk setiap gampong. semua desa di Aceh menerima dana itu dengan jumlah sama, yaitu Rp 565.640.000. Sekitar 10 persen lainnya dibagikan berdasarkan alokasi proporsional. Alokasi proporsional itu ditetapkan dengan SK Bupati/Walikota. Sedangkan Pada tahun 2017, Dana Desa dari APBN untuk Provinsi Aceh meningkat menjadi Rp. 4.892.571.795.000 dari Rp. 3.829.751.986.000.

Rincian dana desa tahun anggaran 2017 Kabupaten Bener Meriah mendapatkan dana sebesar Rp. 174.350.988.000.00 yang di bagikan ke 232 desa. Setiap desa mendapatkan dana sebesar Rp. 751.512.879,31. Anggaran dana desa yang di berikan setiap tahunnya terus mengalami peningkatan.

Desa Gelampang Wih Tenang Uken Adalah salah satu desa yang terletak di Kabupaten Bener Meriah yang mendapatkan anggaran dana desa. Sejak tahun 2015 dana desa yang sudah di terima yaitu Rp.222.699.900,00. Dan terus mengalami peningkatan pada tahun 2017 Desa Gelampang Wih Tenang Uken Sudah menerima anggaran dana desa sebesar Rp. 973.351.708,00. Namun demikian, Banyak terjadi permasalahan dalam pengelolaan anggaran

Efektivitas Realisasi Program Alokasi Dana Desa (ADD) di Desa Gelampang 
dana desa, diantaranya yaitu kurangnya keterbukaan pemerintah terhadap Program ADD mengakibatkan masyarakat kurang memahami program yang di bentuk oleh pemerintah, pelayanan pengurus terhadap masyarakat dirasakan kurang memuaskan. Dari permasalahan tersebut penulis akan meneliti bagaimana efektivitas program ADD di Desa Gelampang Wih Tenang Uken.

Tujuan penelitian ini yaitu sebagai berikut:1) Mengetahui realisasi program ADD di Desa Gelampang Wih Tenang Uken, Kecamatan Permata, Kabupaten Bener Meriah.2) Mengetahui implementasi program ADD di Desa Gelampang Wih Tenang Uken, Kecamatan Permata, Kabupaten Bener Meriah. 3)Mengetahui tingkat keefektifan pelaksanaan dan program ADD di Desa Gelampang Wih Tenang Uken, Kecamatan Permata, Kabupaten Bener Meriah.

\section{Lokasi Objek dan Ruang Lingkup Penelitian}

\section{METODE PENELITIAN}

Penelitian ini dilakukan di Desa Gelampang Wih Tenang Uken, Kecamatan Permata, Kabupaten Bener Meriah, dilaksanakan pada Bulan Juni hingga Agustus 2017. Adapun yang tergabung dalam penelitian ini yaitu seluruh masyarakat Desa Gelampang Wih Tenang Uken. Ruang lingkup penelitian ini terbatas pada Efektivitas Realisasi Program Alokasi Dana Desa (ADD) di Desa Gelampang Wih Tenang Uken, Kecamatan Permata, Kabupaten Bener Meriah.

\section{Metode Penelitian}

Jenis Metode penelitian yang digunakan dalam penelitian ini adalah penelitian metode studi kasus dengan pendekatan yang digunakan adalah pendekatan deskriptif. Teknik pengumpulan data dilakukan dengan menggunakan metode wawancara, observasi dan dokumentasi.

\section{Metode Pengumpulan Data}

Jenis data yang dikumpulkan dalam penelitian ini yaitu terdiri dari data Primer dan data sekunder, data primer di peroleh dari survei, kunjungan ke desa, dinas terkait, BPS, hasil wawancara dan dokumentasi. Sedangkan data sekunder di dapatkan dari kunjungan pustaka, jurnal, dan skripsi.

\section{Metode Analisis}

Data yang diperoleh di lapangan di analisa dengan metode analisis dekskriptif dengan data kualitatif dan kuantitatif . Metode analisis deskriptif yaitu metode yang digunakan untuk menggambarkan atau menganalisis suatu hasil penelitian tetapi tidak digunakan untuk membuat kesimpulan yang lebih luas (Sugiono, 2005).

Untuk mengetahui efektivitas program ADD di Desa Gelampang Wih Tenang Uken. Digunakan rumus sebagai berikut:

Efektivitas Realisasi Program Alokasi Dana Desa (ADD) di Desa Gelampang 


$$
\text { Efektivitas Program }=\frac{\text { Realisasi Program } A D D}{\text { Target Program } A D D} \times 100 \%
$$

(Mahsun. 2009)

Dimana:

Efektivitas Program (EP) Keefektifan program (\%)

Realisasi Program Kerja = Program yang terlaksana (Rupiah/ Tahun)

Target Program $=$ Jumlah Target program yang di ajukan (Rupiah/Tahun)

berikut:

Tabel 1. Tabel Interprestasi Nilai Efektivitas

\begin{tabular}{llc}
\hline NO & Persentase & Kriteria \\
\hline $\mathbf{1}$ & $>100$ & Sangat Efektif \\
$\mathbf{2}$ & $90 \%-100 \%$ & Efektif \\
$\mathbf{3}$ & $80 \%-90 \%$ & Cukup Efektif \\
$\mathbf{4}$ & $60 \%-80 \%$ & Kurang efektif \\
$\mathbf{5}$ & $<60 \%$ & Tidak efektif \\
\hline
\end{tabular}

Sumber: Kepmendagri No.690.900.327

\section{HASIL PENELITIAN DAN PEMBAHASAN}

Implementasi pelaksanaan pengelolaan kegiatan ADD di Desa Gelampang Wih Tenang Uken berjalan dengan baik, kegiatan dilakukan secara terstruktur harus sesuai dengan kebijakan yang telah dibuat. Hal ini dapat dilihat dari persiapan penyusunan daftar usulan penggunaan dana, pelaksanaan kegiatan, pencapaian pelaksananaan program, hingga laporan pertanggung jawaban. Namun masih ada kekurangan diantaranya sistem pengelolaan yang tidak transparan, dan kemampuan pengelolaan yang masih perlunya peningkatan sumber daya manusia.

Capaian tujuan program tergolong sesuai dengan kebijakan yang telah dibuat, hal tersebut dapat di lihat dari realisasi program yang telah terlaksana. Semenjak tiga tahun diadakan program ADD di Desa Gelampang Wih Tenang Uken ada beberapa program yang telah di jalankan yaitu seperti pada tabel berikut:

Efektivitas Realisasi Program Alokasi Dana Desa (ADD) di Desa Gelampang 
Tabel 2. Realisasi Program Yang Telah Terlaksana

\begin{tabular}{|c|c|c|}
\hline No & TAHUN & KEGIATAN YANG TERLAKSANA \\
\hline 1 & 2015 & $\begin{array}{ll}\text { - } & \text { Pembangunan Saluran Air Bersih } \\
\text { - } & \text { Pembuatan Turap Kantor Desa }\end{array}$ \\
\hline 2 & 2016 & $\begin{array}{ll}\text { - } & \text { Pembuatan Rabat Beton } \\
\text { - } & \text { Pembangunan Drainase } \\
\text { - } & \text { Pembukaan Jalan Kebun }\end{array}$ \\
\hline 3 & 2017 & $\begin{array}{l}\text { - Pemeliharaan dan Pembangunan Drainase } \\
\text { - Pembangunan jalan Pemukiman/Aspal } \\
\quad \text { Lapen }\end{array}$ \\
\hline
\end{tabular}

Sumber : Reje Kampung 2017

Realisasi program ADD di Desa Gelampang Wih Tenang Uken sepanjang tahun 2015 dan 2016 sudah banyak pembangunan infrastruktur di antaranya yaitu pembuatan saluran air bersih, turap kantor desa pada tahun 2015 sedangkan pada tahun 2016 yaitu rabat beton, drainase,dan pembukaan jalan kebun. Selain untuk pembangunan, dana ADD juga digunakan sebagai belanja penyelenggaraan Pemerintah Kampung, kegiatan operasional kampung, dan belanja pegawai. Sedangkan untuk kegitan pemberdayaan masyarakat di Desa Gelampang Wih Tenang Uken tidak ada, hal ini dikarenakan sumber daya manusia yang masih minim di daerah tersebut. Alokasi Dana Desa di Gelampang Wih Tenang Uken pada tahun 2017 sudah semakin membaik hal ini di karenakan ada perubahan pengurusan pemerintahan desa, selain itu informasi mengenai ADD sudah mulai di paparkan dibandingkan pada tahun sebelumnya yang masih kekurangan informasi. Berikut adala besaran anggaran dana yang telah di terima oleh Pemerintah Desa Gelampang Wih Tenang Uken dapat di lihat pada tabel:

Tabel 3. Besaran Anggaran Dana Desa Tahun 2015-2017

\begin{tabular}{llll}
\hline No & Tahun Anggaran & Dana Anggaran & Sisa Anggaran \\
\hline $\mathbf{1}$ & 2015 & Rp.222.699.900,00 & Rp 5.484,42 \\
$\mathbf{2}$ & 2016 & Rp. 611.174.000,00 & Rp 5.484,42 \\
\hline $\mathbf{3}$ & 2017 & Rp .973.351.708,00 & Rp 5.484,42 \\
\hline
\end{tabular}

Sumber : Reje Kampung Desa Gelampang Wih Tenang Uken 2017

Berdasarkan hasil penelitian Realisasi kegiatan Program ADD yang dilakukan di Desa Gelampang Wih Tenang Uken yaitu pembangunan berbentuk fisik diantaranya pembangunan rabat beton, drainase, turap kantor desa dan pembanguanan jalan pemukiman/aspal lapen. Implementasi Program ADD di Desa Gelampang Wih Tenang Uken terkendala pada kurangnya transfaransi pemerintah desa sehingga informasi yang di berikan terbatas.

Realisasi program Alokasi Dana Desa (ADD) di Desa Gelampang Wih Tenang Uken tergolong efektif, hal ini dapat dilihat dari laporan pertanggung jawaban desa di mulai dari

Efektivitas Realisasi Program Alokasi Dana Desa (ADD) di Desa Gelampang 
tahun 2015 ( $222.699 .900: 300.000 .000 \times 100 \%=74,23 \%), 2016(611.174 .000: 750.000 .000$ x $100 \%=81,49 \%) 2017,(973.351 .708: 1.000 .000 .000 \times 100 \%=97,33 \%)$. Namun demikian, pengelolaan ADD di Desa Gelampang Wih Tenang Uken masih perlu perbaikan baik di segi pengelolaan maupun sumberdaya manusia. Kagiatan ADD yang dilakukan di Desa tersebut masih terbatas pada pembangunan fisik saja.

Tabel 4. Persentase Efektifitas Realisasi Program ADD

\begin{tabular}{ccc}
\hline No & Tahun & Persentase Efektivitas ADD \\
\hline 1 & 2015 & $(222.699 .900: 300.000 .0000) \times 100 \%=74,23 \%$, \\
2 & 2016 & $(611.174 .000: 750.000 .000) \times 100 \%=81,49 \%$ \\
\hline 3 & 2017 & $(973.351 .708: 1.000 .000 .000) \times 100 \%=97,33 \%$ \\
\hline
\end{tabular}

Sumber: Data diolah 2017

\section{Kesimpulan}

\section{KESIMPULAN DAN SARAN}

1. Realisasi kegiatan Program ADD di Desa Gelampang Wih Tenang Uken berdasarkan hasil penelitian, yaitu pembangunan berbentuk fisik diantaranya pembangunan rabat beton, drainase, turap kantor desa dan pembanguanan jalan pemukiman/aspal lapen.

2. Implementasi Program ADD di Desa Gelampang Wih Tenang Uken masih tergolong kurang baik, penerapan program ADD hanya sebatas pada pembangunan fisik saja, implementasi terkendala pada kurangnya transfaransi pemerintah desa sehingga informasi yang di berikan terbatas. Hal ini dapat dilihat dari penyampaian pelaporan yang tidak melibatkan masyarakat.

3. Program Alokasi Dana Desa di Desa Gelampang Wih Tenang Uken tergolong efektif hal ini dapat di lihat dari pembangunan yang dilaksanakan dan persentase efektivitas ADD yang berjumlah $74,23,81,49 \%$ dan $97,33 \%$.

\section{Saran}

1. Diharapkan kepada pemerintah agar Program ADD di Desa Gelampang Wih Tenang Uken tidak hanya terpaku pada program pembangunan fisik saja, harus di dampingi dengan program pemberdayaan masyarakat.

2. Perlu adanya peningkatan kapasitas mengenai kemampuan dan pemahaman terhadap masyarakatt dan pengurus mengenai pengelolaan Program ADD di Desa Gelampang Wih Tenang Uken.

3. Diharapkan sikap transparansi kepengurusan mengenai pengelolaan ADD dapat di tingkatkan agar memudahkan masyarakat untuk mendapatkat informasi mengenai Program ADD. 


\section{DAFTAR PUSTAKA}

Aljannah, S. 2017. Evaluasi Alokasi Dana Desa (ADD) dalam Menunjang Pembangunan Desa di Kecamatan Tambusai Utara.Universitas Riau. Riau. Jurnal JOM Fekom Vol.4 No 1. Februari 2017.

Badan Pusat Statistik. Internet (setkab.go.id) Diposkan 3 januari 2017.

Davis, Keith dan Newstrom, Jhon W. 2004. Perilaku Dalam Organisasi, Edisi 7 Bahasa Indonesia, Jilid 1. Jakarta . Erlangga

Depdagri. 1997. Kepmendagri No.690.900.327.1996. Tentang Pedoman Pedoman Penilaian dan Kinerja Keuangan.

Effendi, B. 2002. Pembangunan Daerah Otonomi Berkeadilan.Uhaindo dan Offset. Yogyakarta.

Harsono, H. 2002. Implementasi Kebijakan dan Politik. Jakarta. Rinheka Karsa.

IMP. 2009. Pedoman Pengukuran Realisasi Keuangan dan Fisik Kegiatan di Lingkunagn Universitas Negeri Medan. UNIMED. Medan.

Mahsun, Mohamad. 2009. Pengukuran Kinerja Publik. Andi. Yogyakarta.

Rosalinda, O (2014) Dengan Judul Pengelolaan Alokasi Dana Desa (ADD) Dalam Menunjang Pembangunan Pedesaan (Studi Kasus di Desa Segodorejo dan Desa Ploso Kerep, Kecamatan Sumobito, Kabupaten Jombang). Universitas Brawijaya. Malang.

Rozaki, A.S, Eko (2005). Prakarsa Desentralisasi dan Otonomi Desa. Yogyakarta, IRE Press.

Sugiyono. 2005. Metode Penelitian Administrasi. Bandung, Alfabeta.

Sukanto, A. Efektifitas Alokasi Dana Desa (ADD) dan Kemiskinan di Provinsi Sumatera Selatan. Universitas Sriwijaya. Palembang. Jurnal Ekonomi Pembangunan. Vol.12 Nomor 1 Halaman 29-41 Juni 2014.

Syahputra, I. 2016. Efektivitas Pengelolaan Alokasi Dana Desa Pada Desa Lembean Kecamatan Kintamani, Kabupaten Bangli Tahun 2009-2014. Jurnal Jurusan 
Pendidikan Ekonomi (JJPE) Volume: 6 Nomor: 1 Tahun 2016. Universitas Pendidikan Ganesha. Singaraja.

Prabawa, Akbar. 2015. Pengelolaan Alokasi Dana Desa Dalam Pembengunan di Desa Loa Lepu Kecamatan Tenggarong Seberang Kabupaten kutai Kartanegara. Ejournal Ilmu Pemerintahan, Volume 3 No1,2015:227-238, ejournal.ip.fisip-unmul.org. Universitas Mulawarman.

Winamo, Budi. 2008. Kebijakan Publik, Teori den Proses. Med Press.Yogyakarta.

Yulita,R. 2016. Efektifitas Pelaksanaan Penggunaan Alokasi Dana Desa (ADD) di Desa Setako Raya Kecamatan Peranap Kabupaten Indragiri Hulu. Universitas Riau. Riau. Jurnal JOM FISIP Vol. 3 No.2 Oktober 2016.

Zakaria. 2000. Masyarakat Desa di Bawah Rejim Orde Baru . Cetakan Pertama. Jakarta 
Jurnal Ilmiah Mahasiswa Pertanian Unsyiah Volume 3, Nomor 3, Agustus 2018 ww.jim.unsyiah.ac.id/JFP

Efektivitas Realisasi Program Alokasi Dana Desa (ADD) di Desa Gelampang Wih Tenang Uken Kecamatan Permata Kabupaten Bener Meriah (Irfan Hidayat, Lukman Hakim, Zulkarnain) Jurnal Ilmiah Mahasiswa Unsyiah, Vol 3, No 3, 2018: 1-8 